\section{Academic general practice: supported by the RCGP}

This article 1 by one of our esteemed former presidents and academic leaders sets out the history and continued challenges in ways we all recognise, but we want to challenge some claims made in the article. We disagree that the RCGP no longer inspires GPs. We are constantly working to engage with our members and non-members at all stages in their career. The NHS environment for GPs may be causing recruitment and morale problems, but the recent RCGP campaign has been our most successful ever, and we spread our active membership engagement ever wider through social media, conferences, and evidenced resources.

We do not understand the claim that the RCGP 'abandoned' its Research Committee - it chose to develop the Clinical Innovation and Research Centre (CIRC), which has a much wider remit and impact. Under the auspices of CIRC, the Research Surveillance Centre continues to publish weekly reports, and has just had its tender renewed for another 3 years; the Scientific Foundation Board awards research grants that are constantly generating innovative and highly relevant research. The College annually celebrates high-quality primary care research through its Research Paper of the Year award, ${ }^{2}$ and there is a huge regular opportunity for academic units to showcase research and its impacts on practice at both regional and national conferences.

Many current officers and clinical leads additionally hold or have held senior academic appointments; and they all work to encourage relevant, timely research and encourage interested colleagues to follow this path. The RCGP and the Society for Academic Primary Care have regular cross-representation, including with the heads of departments of general practice and GP teaching.

We assure the author that academic general practice continues to be at the heart of the RCGP. Thanks for the challenge - and we respect the lifelong effort made to make this all work, for which we are all grateful.

Amanda Caroline Howe,

Professor of General Practice, University of
East Anglia, Norwich.

E-mail: amanda.howelauea.ac.uk

Helen Stokes-Lampard

Honorary Treasurer, RCGP, Academic Head, Community Based Medical Education Institute of Clinical Sciences, Birmingham.

Imran Rafi,

Senior Lecturer, St George's University of London, London.

Maureen Baker,

Chair, RCGP Council, London.

\section{REFERENCE}

1. Pereira Gray D. Academic general practice: a viewpoint on achievements and challenges. $\mathrm{Br} J \mathrm{Gen}$ Pract 2015, DOI: 10.3399/bjgp15X687481.

2. Salisbury C. RCGP Research Paper of the Year 2014 partnership with patients is an important theme in primary care research. Br J Gen Pract 2015; DOI: 10.3399/bjgp15X687469.

\section{Competing interests}

ACH was an officer of the RCGP until December 2015.

DOI: 10.3399/bjgp16X683089

\section{Response from the CQC: the importance of effective leadership}

The intention of the special measures framework is to make patients, providers, and commissioners aware that we have serious concerns and to identify the need for urgent coordinated support within clear timescales. As you highlighted, ${ }^{1}$ there can be local awareness of issues long before the CQC inspects. We strongly back the need for earlier identification of problems rather than waiting for an inspection to unearth the issues. This will involve closer collaborative working with CCGs, NHS England, and the local health economy.

At the CQC we are passionate about improving standards. We have for the first time provided a comprehensive description of good-quality care. ${ }^{2}$ We encourage improvement by championing examples of good, innovative, and outstanding practice. ${ }^{3}$ Indeed, the vast majority of England's GP practices are providing a good service to their patients, so why are the $4 \%$ rated inadequate falling significantly short? As identified in our State of Health Care report, ${ }^{4}$ the key may be in effective leadership.

The CQC assesses leadership and organisational culture of providers in the 'well-led' key question; by well-led, we mean that the organisation assures delivery of highquality person-centred care, supports learning and innovation, and promotes an open and fair culture. Every practice in special measures has been rated inadequate in 'well-led'

Investing in leadership has consistently been shown ${ }^{5}$ to pay off in the ongoing running of a successful organisation. This has been a central theme in supporting Acute Trusts in special measures, and should be for general practice. The RCGP's Pilot Scheme has been doing essential work. However, we must take more collective responsibility in identifying struggling practices early, championing innovation, driving improvement, and providing long-term support.

Devin Gray,

National Medical Director's Clinical Fellow, Care Quality Commission.

E-mail: devin.graylacqc.org.uk

Nigel Sparrow,

Senior National GP Advisor and Responsible Officer, Care Quality Commission.

Steve Field,

Chief Inspector of General Practice, Care Quality Commission.

\section{REFERENCES}

1. Rendel S, Crawley H, Ballard T. CQC inspections: unintended consequences of being placed in special measures. Br J Gen Pract 2015; DOI: 10.3399/ bjgp15X686809.

2. Care Quality Commission. NHS GP practices and GP out-of-hours services: appendices to the provider handbook. http://www.cqc.org.uk/sites/default/ files/20150327 GP practices provider handbook appendices march 15 update.pdf laccessed 1 Dec 2015).

3. Care Quality Commission. Examples of outstanding practice for GPs. 2015. http://uww.cqc.org.uk/content/ examples-outstanding-practice-gps laccessed 1 Dec 2015).

4. Care Quality Commission. The state of health care and adult social care in England 2014/15. http://wnw. cqc.org.uk/sites/default/files/20151103_state of care web accessible 4.pdf (accessed 1 Dec 2015).

5. King's Fund Commission on Leadership and Management in the NHS. The future of leadership and management in the NHS: no more heroes. http://www.kingsfund.org.uk/sites/files/kf/future-of- 